\title{
The Isolation and Comparative Biological and Physical Characteristics of T-mycoplasmas of Cattle
}

\author{
By D. TAYLOR-ROBINSON, \\ Clinical Research Centre, Harvard Hospital, Salisbury, Wiltshire \\ M. H. WILLIAMS, \\ Bacteriology Department, Welsh National School of Medicine, \\ Royal Infirmary, Cardiff \\ AND D. A. HAIG \\ Institute for Research on Animal Diseases, Compton, Newbury, Berkshire
}

(Accepted for publication 24 May 1968)

SUMMARY

T-mycoplasmas were isolated by a 'colour-change' technique, involving the metabolism of urea, from 16 of 49 slaughtered cows $(33 \%)$. They were encountered more often in the urethra and bladder than in the vagina. Isolations were made usually within 2 days of incubation but occasionally 5 days was required. T-mycoplasmas were isolated in medium without inhibitors from urethral scrapings of a cow and from seminal fluid of a bull. On solid medium, bovine T-mycoplasmas produced colonies of $5^{-1} 2 \mu$ which were similar to those produced by a T-mycoplasma from the human urogenital tract. In liquid medium, the growth cycle of bovine $\mathrm{T}$-mycoplasmas was similar to that of human T-mycoplasmas, being more rapid than that of large colony-forming (classical) mycoplasmas. The presence of serum in the medium was necessary for growth. T-mycoplasmas of bovine origin were affected in a similar way to those of human origin when subjected to ether, heat, freezing and thawing, freeze-drying, antibiotics and thallium acetate; they were more sensitive to erythromycin and thallium acetate than some classical mycoplasmas. The size of the minimal reproductive forms of bovine and human T-mycoplasmas and a classical mycoplasma, Mycoplasma hyorhinis, was similar as judged by filtration experiments. Electron microscopy of bovine and human T-mycoplasmas revealed cells which varied in size from $80 \mathrm{~m} \mu$ to $420 \mathrm{~m} \mu$, and which were bounded by a triple-layered membrane, features similar to known classical mycoplasmas.

\section{INTRODUCTION}

Unlike viruses, mycoplasmas reproduce in cell-free media, and some mycoplasma species produce colonies on agar media which may be as large as I000 $\mu$ in diameter. However, other mycoplasmas produce only very small colonies; these have been termed $\mathrm{T}$-strain mycoplasmas ( $\mathrm{T}=$ tiny), and henceforth will be referred to as T-mycoplasmas. They were first isolated by Shepard (1954) from the human urogenital tract. Because of the small size of the colonies which these organisms produce they have been particularly difficult to study. However, Purcell, Taylor-Robinson, Wong \& Chanock (1966) and Shepard (1966) found, independently, that T-organisms 
of human origin metabolized urea with the production of ammonia. Purcell et al. (I966) incorporated urea and phenol red in liquid medium and observed an alkaline colour change with growth of these mycoplasmas. They were able to measure growth-inhibitory antibody by direct observation: antibody inhibited growth and therefore prevented the occurrence of the alkaline change in the $\mathrm{pH}$ of the medium. Previously we reported (Taylor-Robinson, Haig \& Williams, 1967) the detection of organisms in the urogenital tract of cows by the 'colour change' technique and that these organisms were considered to be T-mycoplasmas. The present communication gives a more detailed account of the isolation of these mycoplasmas from cows and bulls. In addition, their properties are compared with those of $\mathrm{T}$-mycoplasmas isolated from the human urogenital tract and oropharynx and with classical large colony-forming mycoplasmas of bovine and human origin. Evidence is presented to show that T-mycoplasmas of cattle are not L-phase variants of bacteria.

\section{METHODS}

Organisms. The source of strains of classical large colony-forming mycoplasmas used for comparative purposes was described elsewhere (Manchee \& Taylor-Robinson, I968). A T-mycoplasma, designated REOW, isolated from the human genital tract, was supplied by Professor R. E. O. Williams, and a T-mycoplasma, designated 'JoHNson', was isolated from the human oropharynx (Taylor-Robinson \& Purcell, 1966).

Media. Liquid medium for the growth of T-mycoplasmas consisted of Difco PPLO broth (70 ml.), $25 \%$ (w/v) aqueous extract of Distillers Co. Ltd. dried yeast (IO ml.), unheated Burroughs Wellcome horse serum no. $6(20 \mathrm{ml}$.), $0.1 \%$ urea and $0.002 \%$ phenol red; thallium acetate (I/2000) and penicillin (I000 U./ml.) were included in some batches of medium. The medium was adjusted with $\mathrm{O} \cdot \mathrm{I} \mathrm{N}-\mathrm{HCl}$ to between $\mathrm{pH} 7 \cdot 0$ and 6.0. Solid medium consisted of: $(a)$ the liquid medium described above with the addition of $1 \%$ Oxoid Ionagar No. 2; (b), trypticase-soy (T-S) broth (Baltimore Biologicals Ltd., U.S.A.) with $20 \%$ (v/v) unheated horse serum and I \% Ionagar. Urea, phenol red and antibiotics were omitted from some batches of solid medium. Large colony-forming mycoplasmas were grown in the media described above (except T-S medium) in which either $0.1 \%$ arginine or $0.1 \%$ glucose was substituted for urea.

Titration of viable organisms. Suspensions of organisms were titrated by using stainless steel loops (Cooke Engineering Co., Alexandria, Virginia, U.S.A.) in serial ten-fold steps either in screw-cap vials or in the cups of Linbro microtitre plates (Linbro Chemical Co. Inc., New Haven, Conn., U.S.A.). In the latter instance, the cups contained nine drops (about $0.2 \mathrm{ml}$.) of medium and one loopful of the organism suspension was transferred, the loops being boiled between each transfer. Growth of the $\mathrm{T}$-organisms, and those mycoplasmas which metabolized arginine, produced in the medium a change from $\mathrm{pH} 6.5$ to 8.0 or above; those mycoplasmas which metabolized glucose produced a change in the medium from $\mathrm{pH} 7.8$ to 6.0 or less. Vials and microtitre plates were incubated at $36^{\circ}$ until colour changes were complete. One colour-changing unit (ccu) of activity was defined as the highest dilution of the mycoplasma suspension which produced a colour change. Sometimes suspensions of organisms were inoculated on solid medium and colonies counted.

Haemadsorption and haemolysis. Tests for colony haemadsorption were performed as described by Del Giudice \& Pavia (1964) and by Manchee \& Taylor-Robinson 
(1968). Tests for haemolysis production by colonies were done as described by Somerson, Purcell, Taylor-Robinson \& Chanock (1965).

Ether stability test. Liquid medium containing mycoplasmas was mixed with diethyl ether, the final concentration being $20 \%(\mathrm{v} / \mathrm{v})$ ether. The mixtures in I oz. screw-cap bottles were kept at $4^{\circ}$ for $18 \mathrm{hr}$. To remove ether, the mixtures were incubated for I hr at $37^{\circ}$ with the screw-caps loose, after which a stream of nitrogen was passed over the liquid medium while it was gently agitated. Titrations of mycoplasma cultures before and after ether treatment and of control cultures without ether were made.

Freezing and thawing. Mycoplasmas in liquid medium were subjected to alternate cycles of rapid freezing in a freezing mixture and thawing at room temperature. Viable organisms were titrated before and after 10 and 20 cycles of such treatment.

Freeze-drying. Liquid medium containing mycoplasmas was put in Pyrex glass ampoules in $0 . \mathrm{I} \mathrm{ml}$. amounts and dried for a total period of about $24 \mathrm{hr}$ on an Edwards model 5 PS centrifugal freeze-drier. The ampoules were sealed at a final vacuum of less than 20 torr and stored at $4^{\circ}$. The presence of a vacuum was confirmed with a high frequency tester before the ampoules were opened for use.

Antibiotic sensitivity tests. The inhibitory effect of various antibiotics on the growth of mycoplasmas in liquid medium was measured by a micro-technique described previously (Taylor-Robinson, 1967).

Gradocol and millipore membrane filtration. To determine the size of mycoplasma organisms, liquid cultures were filtered through membranes of various average pore diameter (a.p.d.) and the number of organisms before and after filtration was titrated. The experiments were made by filtering samples of a culture through membranes of different a.p.d., and not by using the filtrate of one experiment to pass through a membrane of smaller a.p.d. Experiments with Gradocol membranes (Wright-Fleming Institute, St Mary's Hospital, London) were performed with a positive pressure of no more than $5 \mathrm{lb}$./sq.in. Experiments with Millipore membranes (Millipore Filter Co., Bedford, Mass., U.S.A.) were made with a Swinny adaptor. In some filtration experiments, the medium used to grow the organisms was first filtered through a $220 \mathrm{~m} \mu$ a.p.d. Millipore filter.

Electron microscopy. Organisms for electron-microscope studies were prepared as described by Anderson \& Barile (1965) and were embedded in an Epon-Araldite mixture (Mollenhauer no. I; Mollenhauer, 1964). Sections were cut with a Reichart U. 2 ultramicrotome and were examined in an A.E.I. EM $6 \mathrm{G}$ after staining with saturated ethanolic uranyl acetate and $10 \%(\mathrm{w} / \mathrm{v})$ aqueous lead citrate.

\section{RESULTS}

\section{Isolation of T-mycoplasmas}

Isolation in the presence of antibiotics. At the time of slaughter urogenital tracts of cows were removed. The outer bladder wall was seared with a flamed palate knife and the bladder opened by an incision from the fundus to the neck, after which the incision was carried through the urethra. The vagina was then cut in a similar manner. The bladder epithelium was scraped with a scalpel and the scrapings inoculated into $2 \cdot 0 \mathrm{ml}$. liquid mycoplasma medium contained in screw-capped vials. Specimens were taken in a similar manner from urethra, cervix, and body of the vagina. The vials were 
incubated at $36^{\circ}$ and observed for a change in the colour of the medium from yellow to pink. When this occurred subcultures were made to liquid or solid medium. The solid medium was incubated at $36^{\circ}$ in a humid atmosphere of $5 \%(\mathrm{v} / \mathrm{v}) \mathrm{CO}_{2}$ in nitrogen. Colonies were sought after 24 to $48 \mathrm{hr}$ incubation. A summary of the isolations made from various anatomical sites of 49 slaughtered cows is shown in Table I. Tmycoplasmas were isolated from $16(33 \%)$ of the cows. The results in Table 2 show that, although each anatomical site was not examined with equal frequency, T-mycoplasmas were encountered more often in the urethra and bladder than in the vagina. In most instances, a colour change was observed 2 days after inoculation and incubation of the liquid medium. On three occasions, however, a colour change did not occur until 5 days after inoculation; colour changes on subsequent subculture of each of these three isolates were observed after I to 2 days of incubation.

Table I. Isolation of T-mycoplasmas from slaughtered cows

\begin{tabular}{|c|c|c|c|c|c|c|}
\hline \multirow{3}{*}{$\begin{array}{l}\text { No. of cows } \\
\text { examined }\end{array}$} & \multicolumn{4}{|c|}{ No. of cows from which T-mycoplasmas isolated* from } & \multirow{2}{*}{\multicolumn{2}{|c|}{ Total }} \\
\hline & Urethra & Urethra & Urethra & Bladder & & \\
\hline & alone & bladder & vagina & alone & No. & $\%$ \\
\hline 49 & 12 & $\mathbf{I}$ & $\mathbf{I}$ & 2 & 16 & 33 \\
\hline
\end{tabular}

* Isolation regarded as successful only when subculture accomplished. Some strains were subcultured i times.

Table 2. Details of rate and speed of isolation of T-mycoplasmas from different anatomical sites of the cow

\begin{tabular}{|c|c|c|c|c|c|c|c|}
\hline \multirow{2}{*}{$\begin{array}{l}\text { Anatomical } \\
\text { site }\end{array}$} & \multirow{2}{*}{$\begin{array}{c}\text { No. of } \\
\text { tests }\end{array}$} & \multicolumn{4}{|c|}{$\begin{array}{l}\text { No. of tests in which colour change } \\
\text { observed after indicated days }\end{array}$} & \multicolumn{2}{|c|}{ Isolations } \\
\hline & & I & 2 & 3 & 5 & No. & $\%$ \\
\hline Urethra & 48 & I & 7 & 4 & 2 & I4 & 29 \\
\hline Bladder & 14 & - & 2 & - & I & 3 & $2 J$ \\
\hline Vagina & 9 & - & I & - & - & I & I I \\
\hline Total & 71 & I & IO & 4 & 3 & 18 & 25 \\
\hline
\end{tabular}

On one occasion, a urethral specimen was divided into four portions, A, B, C, D. $A$ was incubated in the usual way and B, after being frozen and thawed once; a colour change occurred after 3 days in both instances. $C$ was held at $4^{\circ}$ for $48 \mathrm{hr}$ before incubation at $36^{\circ}$, and a colour change was not observed until after 7 days. D was treated ultrasonically; no colour change was seen on incubation.

Isolation in the absence of antibiotics. Numerous attempts were made to isolate T-mycoplasmas, in liquid medium and on solid medium, but without antibiotics. Most of these attempts failed because of overgrowth by bacteria. However, successful isolations were made on two occasions by inoculation of solid medium followed by subculture to liquid medium. In the first instance, the specimen was a vaginal scraping from a cow and, after incubation for $48 \mathrm{hr}$, a block of solid medium without bacterial colonies and without observable mycoplasma colonies was transferred to liquid medium. An alkaline colour change of the liquid medium was observed after incubation for 3 days; this medium was subcultured again into liquid medium and then to solid medium. Colonies were observed on the first examination after incubation for 
3 days. The second isolation in antibiotic-free medium was from bull semen and was accomplished in a similar manner to that just described.

\section{Biological and physical characteristics}

Colonies on solid medium. The diameter of bovine T-mycoplasma colonies was about 5-12 $\mu$ after incubation for 24 to $48 \mathrm{hr}$ at $36^{\circ}$; they did not increase in size on continued incubation. Their morphology varied from granular colonies with barely discernible central nipples to smoother colonies with more prominent nipples. (P1. I, fig. I). These colonies were similar in size and morphology to colonies of T-mycoplasmas isolated from the human genital tract (Pl. I, fig. 2, 3). The T-mycoplasma colonies with a nipple were about ten-fold smaller in diameter than those of large colony-forming mycoplasmas, but morphologically similar in appearance to large colony-forming mycoplasmas such as Mycoplasma bovigenitalium of bovine origin (PI. I, fig. 4) and M. hominis of human origin (Pl. I, fig. 5).

Tests for haemadsorption and haemolysis by colonies. Neither phenomenon occurred with colonies of bovine or human T-mycoplasmas tested with human, bovine or guinea-pig erythrocytes. On the other hand, colonies of Mycoplasma pneumoniae adsorbed the three species of erythrocytes and produced clear areas of haemolysis when overlayed with guinea-pig erythrocytes in agar medium.

Metabolic activity. No colour changes were observed in liquid media containing $0.1 \%$ arginine or $0.1 \%$ glucose inoculated with different concentrations of stock bovine T-organisms and incubated at $36^{\circ}$. Under the same conditions, growth of both bovine and human T-mycoplasmas in medium containing $0.1 \%$ urea resulted in a colour change from yellow to pink, the $\mathrm{pH}$ changing from 7.0 to 7.9 or above (see Fig. I). In addition, solid medium containing $0.1 \%$ urea inoculated with stock suspensions of both bovine and human T-mycoplasmas developed a similar colour change on appearance of colonies.

Growth in liquid medium. The growth of bovine T-mycoplasma strain $\mathrm{U} 8$, and T-mycoplasma REOw from the human genital tract in liquid medium with urea is illustrated in Fig. I; the growth of the large colony-forming mycoplasmas $\mathrm{Myco-}$ plasma hominis and $M$. bovigenitalium in media with arginine and glucose, respectively, is also shown. The rate of growth of bovine and human T-mycoplasmas was similar, maximum titres being obtained within $32 \mathrm{hr}$. In both instances, the decline in number of viable organisms was rapid. This was in contrast to the slower rate of growth, higher maximum titres, and slower decline in the number of viable organisms of the classical large colony-forming mycoplasmas.

Requirement for serum. In an initial experiment, liquid medium without serum was inoculated with bovine T-mycoplasma strain U 8. A change from $\mathrm{pH} 6.9$ to 7.7 was detected after incubation for $54 \mathrm{hr}$ at $36^{\circ}$. However, no colour change was observed on subculture in serum-free medium. It seemed likely that the growth, which as judged by the $\mathrm{pH}$ change, was observed in the first instance, was due to the presence of a small concentration of horse serum $(0.2 \%)$ introduced with the inoculum. This was confirmed in a further experiment (Fig. 2) in which attempts were made to grow the same bovine organism in medium containing different concentrations of horse serum. There was rapid growth in medium containing $20 \%(\mathrm{v} / \mathrm{v})$ horse serum, slower growth in medium containing $2 \%(\mathrm{v} / \mathrm{v})$ horse serum, and no growth in medium with $0.02 \%$ (v/v) serum. 


\section{Effects of various chemical and physical factors}

Ether. Suspensions of two bovine T-mycoplasmas (U 8, U 20), one human T-mycoplasma (JOHNSON), and two classical large-colony-forming mycoplasmas, Mycoplasma bovigenitalium and $M$. pneumoniae, were treated for $18 \mathrm{hr}$ with $20 \%(\mathrm{v} / \mathrm{v})$ diethyl ether. The results in Table 3 show that such treatment killed the T-mycoplasmas and the classical mycoplasma species.
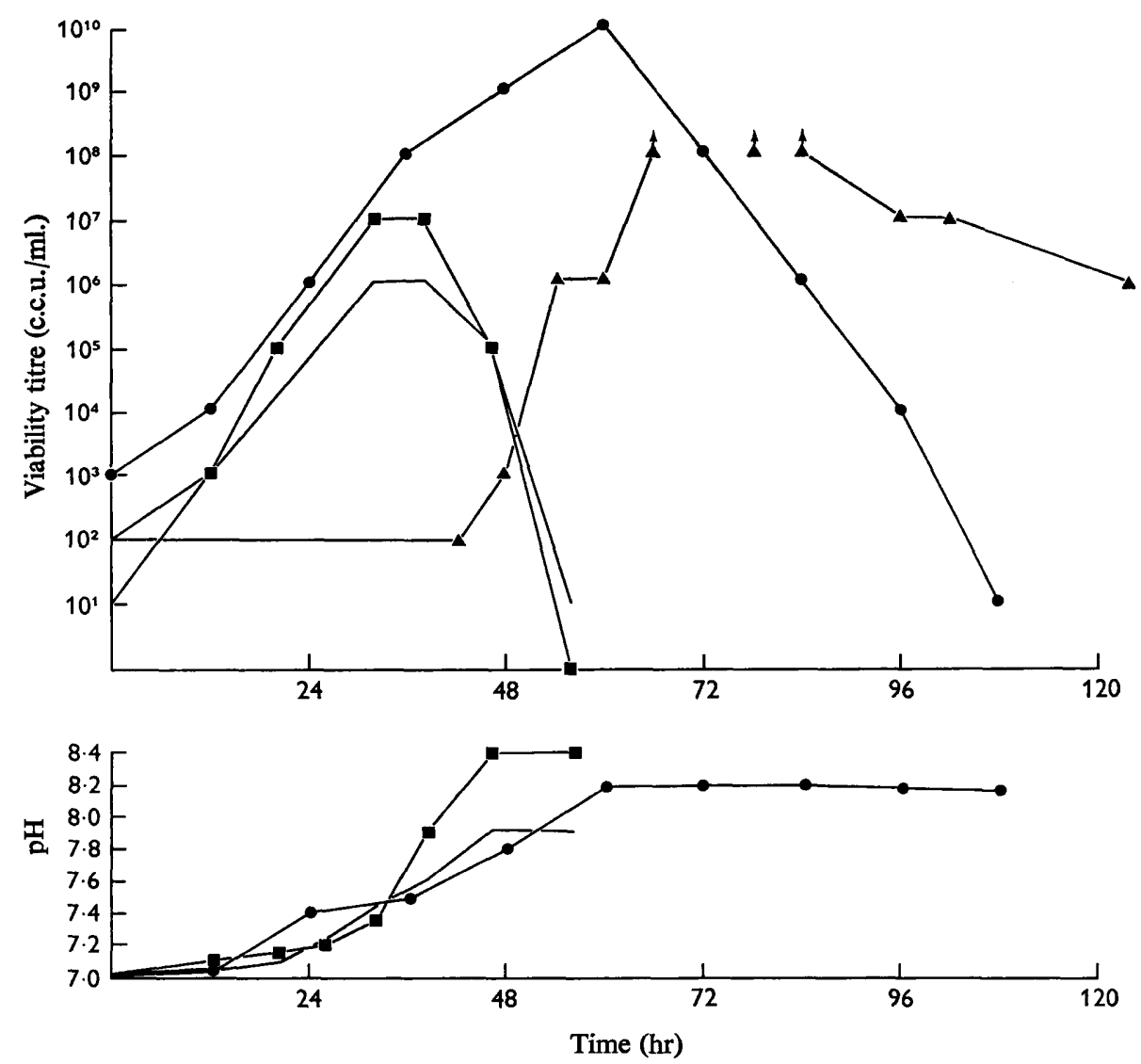

Fig. I. Growth of bovine and human T-mycoplasmas in liquid medium with $0.1 \%$ urea; growth of Mycoplasma hominis in same medium with $0.1 \%$ arginine; growth of $M$. bovigenitalium in same medium with $0.1 \%$ glucose. Changes in $\mathrm{pH}$ of the media also recorded except for $M$. bovigenitalium. $-\longrightarrow, M$. hominis; $\Delta-\Delta, M$. bovigenitalium;

T-mycoplasma REOW (human); — $\longrightarrow$ T-mycoplasma U/8 (bovine).

Heat. As shown in Table 3, none of the previously mentioned mycoplasmas, except $M$. hominis, suspended in liquid medium survived heating at $56^{\circ}$ for $5 \mathrm{~min}$.

Freezing and thawing. The human oral T-mycoplasma JoHNSON was apparently unaffected by 20 cycles of freezing and thawing, whereas the numbers of viable organisms of the other T-mycoplasmas tested were decreased by roo-fold or more (Table 3). A similar variation was observed for the large colony-forming mycoplasmas that were examined. 
Freeze-drying. Bovine T-mycoplasma u 8, human strain REOw, Mycoplasma hominis, and $M$. pneumoniae were freeze-dried and held at $4^{\circ}$ for up to I month. The preparations were then suspended in liquid medium and tested for viability. As shown in Table 3, the number of viable $\mathrm{U} 8$ organisms was apparently not decreased by such treatment, although the number of viable organisms in freeze-dried preparations of other mycoplasmas was decreased Io- to Ioo-fold. The method is therefore useful not only for the preservation of large colony-forming mycoplasmas, but also for T-mycoplasmas of bovine and human origin.

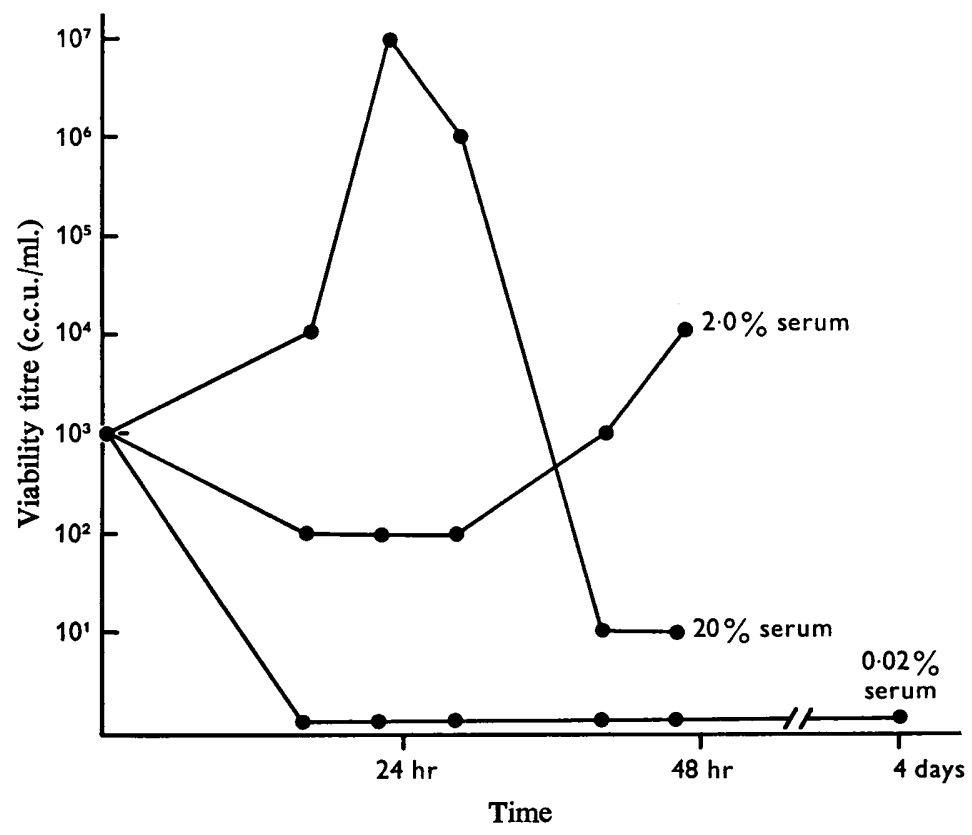

Fig. 2. Growth of bovine T-mycoplasma $\mathrm{U} 8$ in liquid medium containing different concentrations of horse serum.

Table 3. Effect of ether and various physical procedures on the viability of $T$-mycoplasmas and large colony-forming mycoplasmas of bovine and human origin

Titre of viable mycoplasma organisms in colour changing units per $\mathrm{ml}$. (c.c.u./ml.)

\begin{tabular}{|c|c|c|c|c|c|c|}
\hline \multirow[b]{4}{*}{ Mycoplasma } & \multicolumn{6}{|c|}{$\begin{array}{c}\text { Titre of viable mycoplasma organisms in colour } \\
\text { changing units per ml. (c.c.u./ml.) }\end{array}$} \\
\hline & \multirow{3}{*}{$\begin{array}{c}\text { Before } \\
\text { treat- } \\
\text { ment }\end{array}$} & \multicolumn{5}{|c|}{ After treatment with } \\
\hline & & \multirow{2}{*}{$\begin{array}{c}\text { Ether: } \\
\text { I } 8 \mathrm{hr} \\
\text { at } 4^{\circ}\end{array}$} & \multirow{2}{*}{$\begin{array}{l}\text { Heat: } \\
5 \text { min. } \\
\text { at } 56^{\circ}\end{array}$} & \multicolumn{2}{|c|}{ Freezing and thawing } & \multirow{2}{*}{$\begin{array}{l}\text { Freeze- } \\
\text { drying }\end{array}$} \\
\hline & & & & Io cycles & 20 cycles & \\
\hline บ 8 & $10^{3 \cdot 5}$ & $<$ IO & $<$ IO & $10^{3}$ & $10^{1}$ & $10^{4}$ \\
\hline U 20 & $10^{5}$ & $<$ 10 & $<$ IO & $10^{4 \cdot 5}$ & $10^{3}$ & n.t. \\
\hline REOW & $10^{5}$ & $<10$ & $<$ IO & $10^{8 \cdot 5}$ & $10^{8}$ & $10^{8}$ \\
\hline JOHNSON & $10^{4}$ & $<10$ & $<$ IO & $10^{4}$ & $10^{4}$ & n.t. \\
\hline M. bovigenitalium & $10^{3}$ & $<10$ & $<10$ & $10^{2}$ & $10^{1}$ & n.t. \\
\hline$M$. hominis (PG 2I) & $10^{6 \cdot 5}$ & $<10$ & $10^{3}$ & $10^{4 \cdot 5}$ & $10^{4 \cdot 5}$ & $10^{4 \cdot 5}$ \\
\hline M. pneumoniae (FH) & $10^{4}$ & $<$ I0 & $<10$ & $10^{4}$ & $10^{4}$ & $10^{3}$ \\
\hline
\end{tabular}




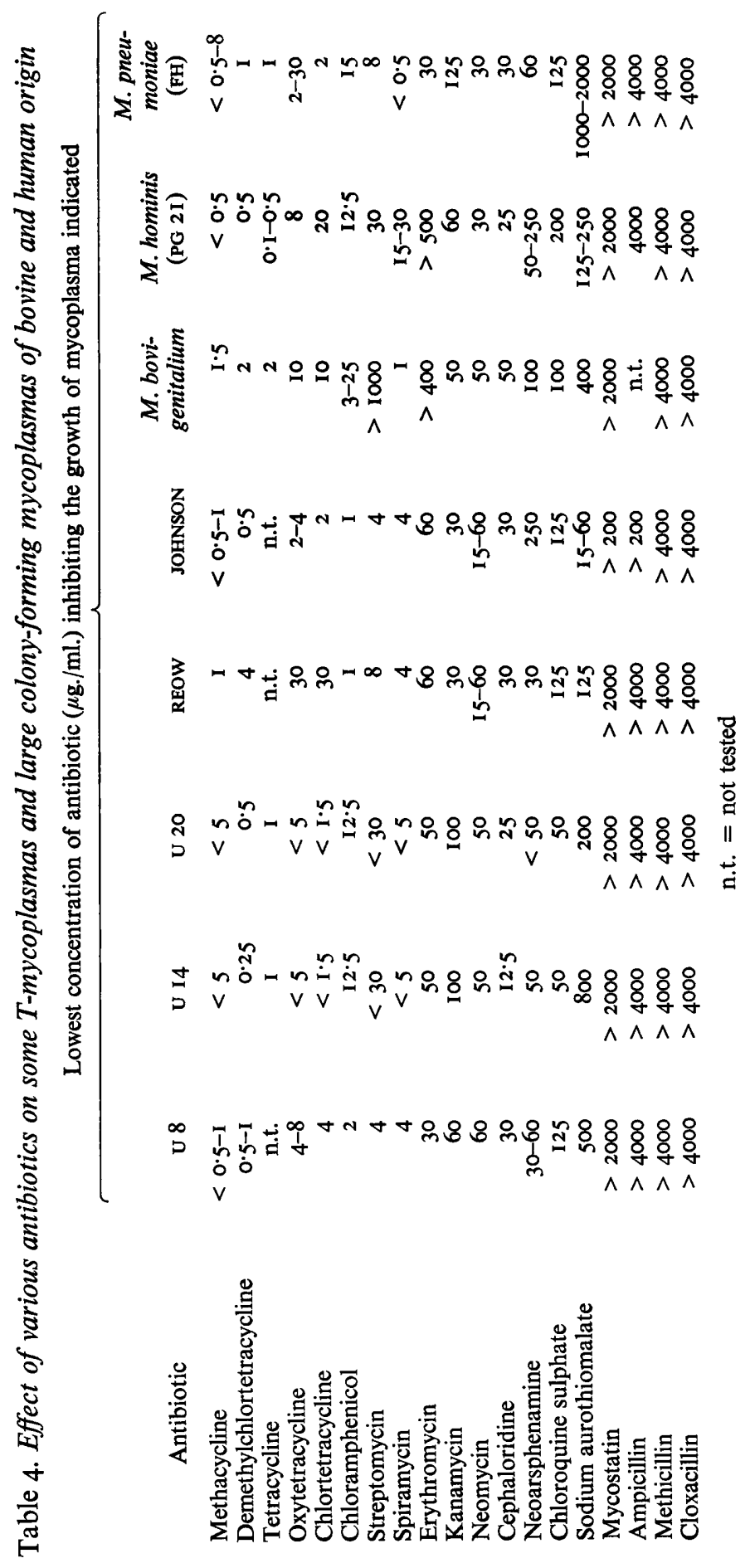


Effect of antibiotics. The effect of a variety of antibiotic drugs, shown in Table 4, on the growth of bovine T-mycoplasmas (U 8, U I4, U 20) and human T-mycoplasmas (REOW, JOHNSON) was compared with their effect on Mycoplasma bovigenitalium, $M$. hominis and $M$. pneumoniae. The spectrum of inhibitory activity was similar in tests with T-mycoplasmas of both bovine and human origin. The tetracycline group of antibiotics was the most effective, whereas the penicillins, including the latest synthetic forms, were not inhibitory at the highest concentration tested. Shepard, Lunceford \& Baker (1966) pointed out the greater susceptibility to erythromycin of $M$.pneumoniae and T-mycoplasmas of human origin in comparison with other mycoplasmas. In the present work, the T-mycoplasmas of bovine origin behaved similarly in this respect. Apart from this, in their sensitivity to other antibiotics, all the T-mycoplasmas tested were similar to the large colony-forming mycoplasmas.

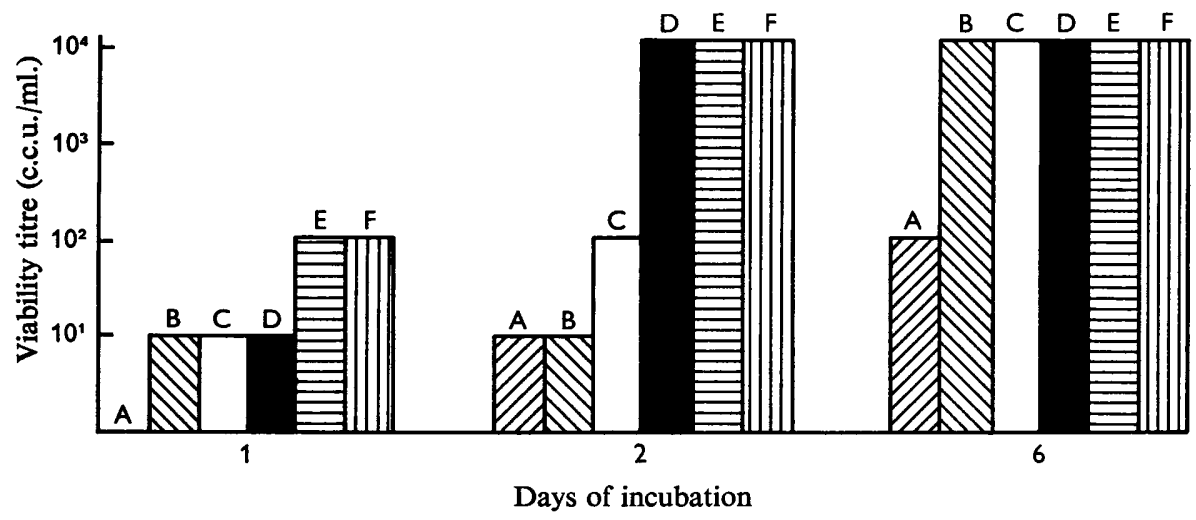

Fig. 3. Growth of bovine T-mycoplasma $\mathrm{U} 8$ in liquid medium containing different concentrations of thallium acetate. Titres recorded at three different times of incubation. $\mathrm{A}=0.4 \%$ thallium; $\mathrm{B}=0.2 \%$ thallium; $\mathrm{C}=0.1 \%$ thallium; $\mathrm{D}=0.05 \%$ thallium; $\mathrm{E}=0.025 \%$ thallium; $\mathrm{F}=$ no thallium.

Effect of thallium acetate. Shepard (1967) and Shepard \& Lunceford (1967) observed that concentrations of thallium which did not inhibit the growth of large colony-forming mycoplasmas did inhibit the growth of T-mycoplasmas isolated from the human urogenital tract. Therefore, the inhibitory effect of thallium on the growth in liquid medium of bovine and human T-mycoplasmas was compared with its effect on the growth of several large colony-forming mycoplasmas. Low concentrations of thallium acetate (I/2000 dilution) had an initial inhibitory effect on growth, although on continued incubation, growth occurred to as high a titre as without thallium acetate. This is illustrated in Fig. 3 with the bovine T-mycoplasma strain U 8. With Mycoplasma hominis this early inhibitory effect was not observed, even with high concentrations of thallium acetate. The results in Table 5 were recorded after prolonged incubation of the tests, when growth of organisms had ceased to be observed. All the T-mycoplasmas were completely or almost completely inhibited by $0.2 \%$ or $0.5 \%$ (w/v) thallium acetate, whereas $M$. bovigenitalium and $M$. hominis were unaffected by $0.8 \%$ thallium acetate. On the other hand, the behaviour of $M$. pneumoniae was more like that of the T-mycoplasmas than that of the other large colony-forming mycoplasmas.

Filtration experiments. From previous filtration experiments (Ford \& Macdonald, 
I963; Klieneberger-Nobel, 1962), it was known that T-organisms of human origin were similar in size to classical large colony-forming mycoplasma organisms. To determine the size of T-mycoplasmas of bovine origin, strains $\mathrm{U} 8$ and $\mathrm{U} 20$ were filtered and the results compared with those obtained for human strain REOw and the large colony-forming species Mycoplasma hyorhinis.

Table 5. Effect of thallium acetate on the growth of T-mycoplasmas and large colony-forming mycoplasmas of bovine and human origin

Titre of mycoplasma (c.c.u./ml.) in medium containing indicated concentration of thallium acetate

\begin{tabular}{|c|c|c|c|c|c|c|}
\hline Mycoplasma & Nil & $0.05 \%$ & $0.1 \%$ & $0.2 \%$ & $0.4 \%$ & $0.8 \%$ \\
\hline u 8 & $10^{4}$ & $10^{4}$ & $10^{4}$ & $10^{4}$ & $10^{2}$ & n.t. \\
\hline U 20 & $10^{3}$ & $10^{3}$ & $10^{4}$ & $10^{1}$ & $<10$ & n.t. \\
\hline REOW & $10^{8}$ & $10^{5}$ & $10^{6}$ & $10^{5}$ & $10^{1}$ & n.t. \\
\hline JOHNSON & $10^{4}$ & $10^{4}$ & $10^{4}$ & $10^{1}$ & $<$ I0 & n.t. \\
\hline M. bovigenitalium & $10^{8}$ & n.t. & $10^{5}$ & $10^{8}$ & $10^{5}$ & $10^{6}$ \\
\hline M. hominis (PG 2I) & $10^{\prime \prime}$ & n.t. & $10^{8}$ & $10^{8}$ & $10^{8}$ & $10^{\circ}$ \\
\hline M. pneumoniae (FH) & $10^{5}$ & n.t. & $10^{5}$ & $10^{5}$ & $10^{4}$ & $10^{3}$ \\
\hline
\end{tabular}

Table 6. Filtration of bovine and human T-mycoplasmas and Mycoplasma hyorhinis through Millipore membranes

Titre of viable organisms (c.c.u./ml.) before and after filtration through membranes of indicated a.p.d.

Mycoplasma*
U 8
U 8
U 20
U 20
REOW
M. hyorhinis (s 7)
M. hyorhinis (s 7)

$\begin{array}{ccccc}\text { After } & & & \\ \text { Before } & 650 \mathrm{~m} \mu & 450 \mathrm{~m} \mu & 300 \mathrm{~m} \mu & 220 \mathrm{~m} \mu \\ 10^{5} & 10^{5} & 10^{4} & 10^{8} & 10^{3} \\ 10^{5} & 10^{4} & 10^{3} & <10 & <10 \\ 10^{4} & \text { n.t. } & 10^{4} & 10^{3} & 10^{1 \cdot 5} \\ 10^{5} & 10^{4} & 10^{5} & <10 & <10 \\ 10^{5} & 10^{9} & 10^{1} & <10 & <10 \\ 10^{8} & 10^{8} & 10^{8} & 10^{8} & 10^{6} \\ 10^{7} & \text { n.t. } & 10^{6} & 10^{6} & 10^{4}\end{array}$

* All the organisms used in these experiments were grown in medium which had been pre-filtered through a Millipore membrane of $220 \mathrm{~m} \mu$ a.p.d.

n.t. = not tested.

Filtration with Gradocol membranes. The mycoplasmas mentioned were filtered through membranes of various a.p.d. and were found to behave similarly; none of the organisms passed through membranes of $500 \mathrm{~m} \mu$ a.p.d. This was possibly due to the fact that the filtrations were not performed sequentially. However, this possibility was not examined because experiments with Gradocol membranes were abandoned in view of the availability of Millipore membranes and the greater ease of manipulating them.

Millipore membranes. The mycoplasmas mentioned were grown in liquid medium which had been filtered through a Millipore membrane of $220 \mathrm{~m} \mu$ a.p.d. and the cultures were then filtered through membranes of various a.p.d. The results are shown in Table 6. Organisms of each mycoplasma strain passed through membranes of $220 \mathrm{~m} \mu$ a.p.d. in at least one experiment, although consistent results in successive 
experiments were not obtained with the T-mycoplasmas. T-mycoplasmas of bovine origin did not differ from those of human origin in this respect. The possibility that the proportion of organisms of a particular size might vary at different stages of the growth cycle was examined. Mycoplasma strains $\mathrm{U} 8$ and $\mathrm{U} 20$ were harvested at various times of incubation at $36^{\circ}$ between $18 \mathrm{hr}$ and $72 \mathrm{hr}$, and filtered. There was no indication that the organisms varied in size at different stages in the growth cycle since the proportion which passed through a particular membrane was approximately the same for each time of incubation. Although the reason for the inconsistent results was not established, it was clear that the various cultures, including those of the bovine T-mycoplasmas, contained a heterogeneous population of organisms (viable units) of different size, some of which were capable of passing through membranes of $220 \mathrm{~m} \mu$ a.p.d.

\section{Electron microscopy}

To establish more accurately the size of the T-mycoplasma organisms and to study their ultrastructure, specimens of bovine strain $U 8$ and human strain REOW were examined by electron microscopy. Preparations of strain U 8 and strain REOW both contained organisms varying in size from 80 to $420 \mathrm{~m} \mu$. Organisms of both these mycoplasma strains were bounded by a triple-layered membrane, $85-95 \AA$ thick (P1. 2, figs. 6, 7). The outer and inner components of the membrane were electron-dense and the middle component electron-transparent. Within the cytoplasm were electrondense spheres and electron-transparent spheres, usually arranged peripherally. Within some electron-transparent areas could be seen nucleic acid fibrils $30-40 \AA$ in diameter. In these various features, the $T$-mycoplasmas of both bovine and human origin appeared to be similar to known large colony-forming mycoplasmas previously described by Anderson \& Barile (1965).

\section{DISCUSSION}

There are numerous reports on the isolation of large colony-forming mycoplasmas from both the respiratory and genital tracts of cattle (Leach, 1967), but T-mycoplasmas have not previously been detected. In the present work, T-mycoplasmas were isolated from $33 \%$ of cows and some recent findings (D. Taylor-Robinson, M. Thomas \& P. Dawson, unpublished) indicate that they may be isolated even more frequently from apparently healthy bulls. T-mycoplasmas have been isolated from the urogenital tract of $34 \%$ of apparently healthy human male subjects (Ford \& DuVernet, I963) which makes it difficult to determine whether they play a causative role in non-specific urethritis. Likewise, because of their widespread occurrence in cattle, it would be extremely difficult to associate bovine $T$-mycoplasmas with disease. Nevertheless, it is interesting that $\mathrm{T}$-organisms have been isolated not only from the vagina and urethra but also from the bladder of slaughtered cows. We do not know, however, whether these T-organisms are present within the bladder during life, since it is possible that there is back-spread from the posterior urethra post-mortem. In this connexion, it would be of value to examine kidneys for the presence of T-mycoplasmas. It was of interest that in several instances T-mycoplasmas were detected as late as 5 days after the beginning of incubation of the material. This is contrary to the concept of a rapid growth cycle. However, a slower rate of growth may be observed in the presence of an inhibitor such as thallium acetate, or if the organisms are present initially in very 
small numbers. The latter possibility seems likely in the specimens from cows, and we do not believe that these strains, particularly since they grew rapidly on subsequent subculture, differ in any respect from those that were isolated more rapidly. By the same reasoning it does not seem likely to us that T-mycoplasmas from man, such as the Boston T-strain (Kundsin, Driscoll \& Ming, 1967), isolated after several days of incubation, represent mycoplasmas which possess fundamentally different characteristics from other T-mycoplasmas.

The best possible defence against the criticism that the bovine T-mycoplasmas might be L-phase varients of bacteria was isolation in medium without any inhibitors. Isolation attempts with materials passed through Millipore filters of $450 \mathrm{~m} \mu$ a.p.d. were not successful. The filtrates were bacteria-free but did not yield T-organisms. In retrospect this is not surprising, since the results of experiments with membrane filters and stock T-mycoplasma cultures suggest that a small number of T-mycoplasma organisms might easily be removed by filters of such a.p.d. After numerous attempts, we made successful isolations in the absence of inhibitors, by inoculating directly on solid medium rather than attempting to isolate directly in liquid medium. The isolation of T-mycoplasmas from bull semen was undertaken initially because we felt that semen might contain few bacteria and this approach facilitate isolation without antibiotics. This notion was incorrect although we did isolate from semen without antibiotics on one occasion by direct inoculation of solid medium. After we were satisfied that isolation without antibiotics was possible, we did not pursue this issue because of the difficulties involved, and we recommend for routine purposes isolation by the colourchange technique with liquid medium containing antibiotics. It is worth noting that those strains that were isolated in the absence of antibiotics grew rapidly, produced small colonies, and metabolized urea in a similar way to the more fully characterized strains isolated in the presence of antibiotics.

\section{Table 7. Summary of differences between T-mycoplasmas of bovine and human origin and large colony-forming mycoplasmas}

\begin{tabular}{|c|c|c|}
\hline Condition & $\begin{array}{l}\text { T-myco- } \\
\text { plasmas }\end{array}$ & $\begin{array}{l}\text { Large colony- } \\
\text { forming } \\
\text { mycoplasmas }\end{array}$ \\
\hline Colonies small & + & - \\
\hline Rapid growth cycle & + & - \\
\hline Maximum viable titre high & - & + \\
\hline Urea metabolized & + & - \\
\hline $\begin{array}{l}\text { Arginine and/or glucose } \\
\text { metabolized }\end{array}$ & - & + \\
\hline Inhibition by erythromycin & $+^{*}$ & - \\
\hline Inhibition by thallium acetate & $+*$ & - \\
\hline
\end{tabular}

* Mycoplasma pneumoniae inhibited also.

Shepard (1967) reported that T-mycoplasmas of human origin produce lysis of guinea-pig, sheep and human erythrocytes. We observed no haemolysis with T-mycoplasmas of human origin and those of bovine origin behaved likewise in our hands. The similarity between human and bovine strains is emphasized by our inability to distinguish between them in a variety of tests. In addition, both bovine and human T-mycoplasmas have many properties which are similar to those of the large colony-forming myco- 
plasmas. In particular, electron microscopy studies, which have been reported briefly before (Williams, 1967), show their close similarity. However, there are some notable differences between T-mycoplasmas and other mycoplasmas which are summarized in Table 7 . The relative sensitivity of T-organisms to thallium acetate is of practical importance, since this inhibitor is frequently used in mycoplasma media. Shepard (I967) and Shepard \& Lunceford (1967) advocate that thallium acetate should not be used at all for primary isolation. Certainly one should be aware of its inhibitory effect, but in our experience the consequent increase in bacterial contamination does not justify the exclusion of thallium acetate and we have employed amounts of $1 / 2000$ to $\mathrm{I} / 4000$ with success. Finally, T-mycoplasmas do not, in general, grow to as high a titre as other large colony-forming mycoplasmas. For this reason, it is difficult to prepare antigens for the production of antisera in rabbits. Consequently, serological work is difficult, although possible by the metabolic inhibition-technique (Purcell et al. 1966; Purcell et al. 1967; Ford, 1967), and will be reported later.

D.T.-R. is receiving support from the World Health Organisation for reference work on mycoplasmas. M.H.W. was in receipt of support from the Arthritis and Rheumatism Council.

The authors are grateful for the excellent technical assistance of Miss Jean Addey, Mrs Susan Beveridge, Mrs Jan Wimpenny and Mrs Ann Colwill.

\section{REFERENCES}

ANDERSON, D. R. \& BARILE, M. F. (1965). Ultrastructure of Mycoplasma hominis. J. Bact. 90, 180.

Del GiUdice, R. A. \& Pavia, R. (1964). Hemadsorption by Mycoplasma pneumoniae and its inhibition with sera from patients with primary atypical pneumonia. Bact. Proc. p. 71.

FoRD, D. K. (1967). Relationships between Mycoplasma and the etiology of nongonococcal urethritis and Reiter's syndrome. Ann. N.Y. Acad. Sci. 143, 501 .

FORD, D. K. \& DUVERNET, M. (1963). Genital strains of human pleuropneumonia-like organisms. Br. J. ven. Dis. 39, 18.

FORD, D. K. \& MACDONALD, J. (1963). Morphology of human genital “ 'T-strain” pleuropneumonialike organisms. J. Bact. $85,649$.

KLIENEBERGER-Nobel, E. (1962). Pleuropneumonia-Like Organisms (PPLO). Mycoplasmataceae. p. 6I. London: Academic Press Inc.

Kundsin, R. B., Driscoll, S. G. \& Ming, P.-M. L. (1967). Strain of Mycoplasma associated with human reproductive failure. Science, N.Y. 157, 1573 .

LEACH, R. H. (1967). Comparative studies of mycoplasma of bovine origin. Ann. N.Y. Acad. Sci. I43, 305.

MANCHEE, R. J. \& TAYLOR-RoBInSON, D. (I968). Haemadsorption and haemagglutination by mycoplasmas. J. gen. Microbiol. 50, 465.

Mollenhauer, H. H. (1964). Plastic embedding mixtures for use in electron microscopy. Stain Technol. 39, II I.

Purcell, R. H., Taylor-Robinson, D., Wong, D. \& Chanock, R. M. (I966). A colour test for the measurement of antibody to T-strain mycoplasmas. J. Bact. 92, 6.

Purcell, R. H., Wong, D., Chanock, R. M., Taylor-Robinson, D., Canchola, J. \& Valdesuso, J. (1967). Significance of antibody to Mycoplasma as measured by metabolic-inhibition techniques. Ann. N.Y. Acad. Sci. 143, 664.

ShEPARD, M. C. (1954). The recovery of pleuropneumonia-like organisms from Negro men with and without nongonococcal urethritis. Am. J. Syph. Gonor. ven. Dis. 38, I 3.

ShEPARD, M. C. (1966). Human mycoplasma infections. Health Lab. Sci. 3, I63.

ShEPARD, M. C. (1967). Cultivation and properties of T-strains of Mycoplasma associated with nongonococcal urethritis. Ann. N.Y. Acad. Sci. r43, 505. 
SHEPARD, M. C. \& LUNCEFORD, C. D. (1967). Occurrence of urease in T-strains of Mycoplasma.J. Bact. 93, 1513 .

ShePARD, M. C., LunCeford, C. D. \& BAKer, R. S. (1966). T-strain mycoplasma: selective inhibition by erythromycin in vitro. Br. J. ven. Dis. 42, $2 \mathrm{I}$.

Somerson, N. L., Purcell, R. H., Taylor-Robinson, D. \& Chanock, R. M. (1965). Hemolysin of Mycoplasma pneumoniae. J. Bact. 89, 813.

TAYLOR-RoBInSON, D. (I967). Mycoplasmas of various hosts and their antibiotic sensitivities. Postgrad. med. J. 43 (Suppl.), 100.

Taylor-Robinson, D. \& Purcell, R. H. (1966). Mycoplasmas of the human urogenital tract and oropharynx and their possible role in disease: a review with some recent observations. Proc. roy. Soc. Med. 59, II 12.

Taylor-Robinson, D., Haig, D. A. \& Williams, M. H. (1967). Bovine T-strain Mycoplasma. Ann. N.Y. Acad. Sci. 143, 517.

Williams, M. H. (1967). Electron microscopy of T-strains. Ann. N. Y. Acad. Sci. 143, 397.

\section{EXPLANATION OF PLATES}

Plate I

Fig. I. Colonies of bovine T-mycoplasma u 8 after $30 \mathrm{hr}$ incubation at $36^{\circ}$. Largest colony $10 \mu$ diameter $(\times \mathbf{I}, 400)$.

Fig. 2. A colony of human T-mycoplasma REOW after $30 \mathrm{hr}$ incubation at $36^{\circ}$. Smooth appearancewith prominent nipple. $10 \mu$ diameter $(\times 1,4,0)$.

Fig. 3. Similar to fig. 2. Granular appearance with less prominent nipple. $8 \mu$ diameter $(\times \mathrm{I} 8,000)$.

Fig. 4. Colonies of Mycoplasma bovigenitalium after $72 \mathrm{hr}$. incubation at $36^{\circ} .70-\mathrm{I} 80 \mu$ diameter. $(\times 380)$.

Fig. 5. Colonies of Mycoplasma hominis after $72 \mathrm{hr}$ incubation at $36^{\circ} \cdot 50-100 \mu$ diameter $(\times 300)$.

\section{Plate 2}

Fig. 6. Ultrathin section of T-mycoplasma $U$ 8. Cells $200-400 \mathrm{~m} \mu$ showing membrane $(m)$, electrondense spheres $(d)$, electron-transparent spheres $(t)$ and fibrils $(f)(\times 125,000)$.

Fig. 7. Ultrathin section of T-mycoplasma REOw. Cells $200-400 \mathrm{~m} \mu$ showing similar features to those of Pl. 2, fig. 6. $(\times 60,000)$. 
Journal of General Microbiology, Vol. 54, No. I

Plate I
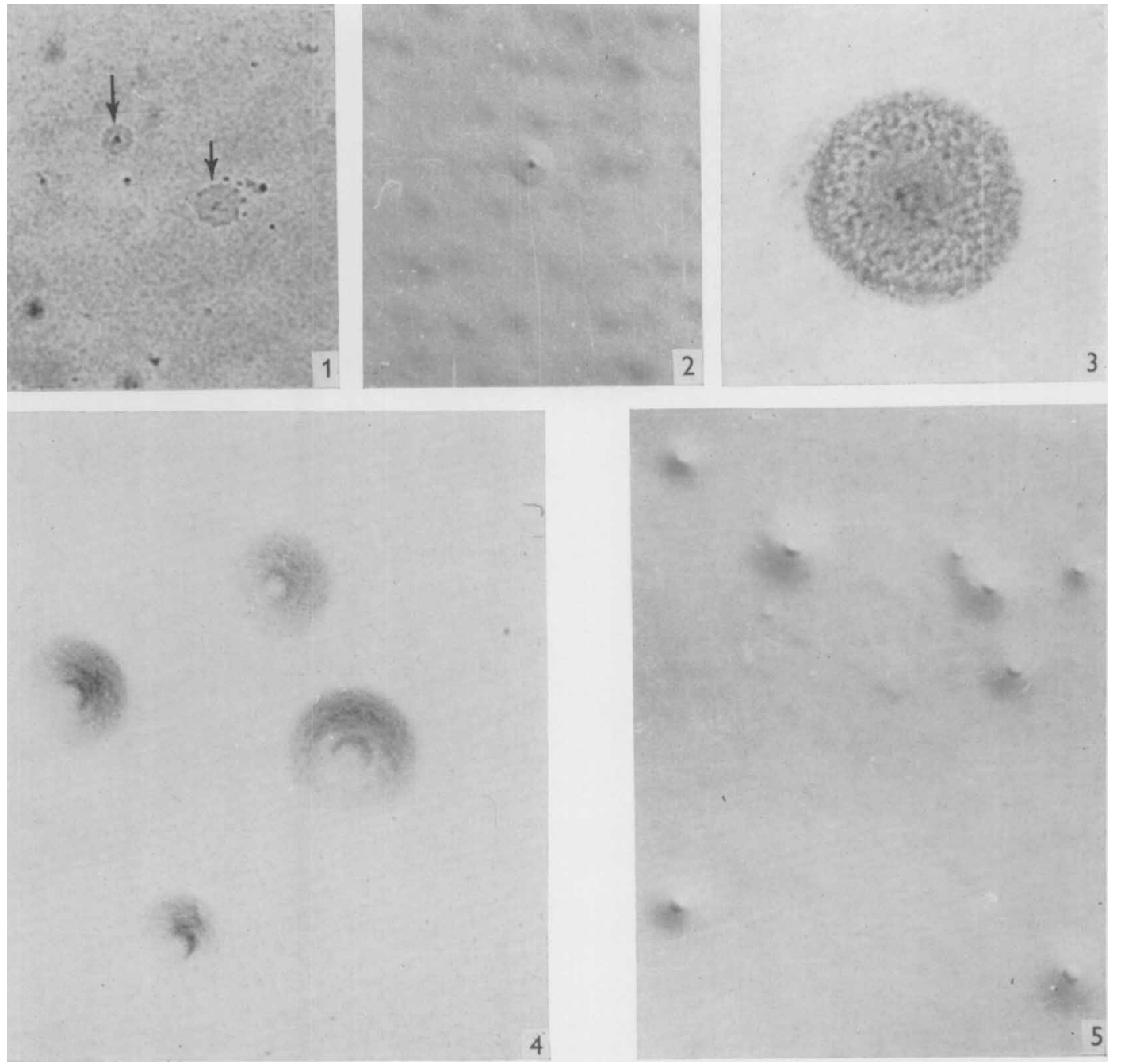


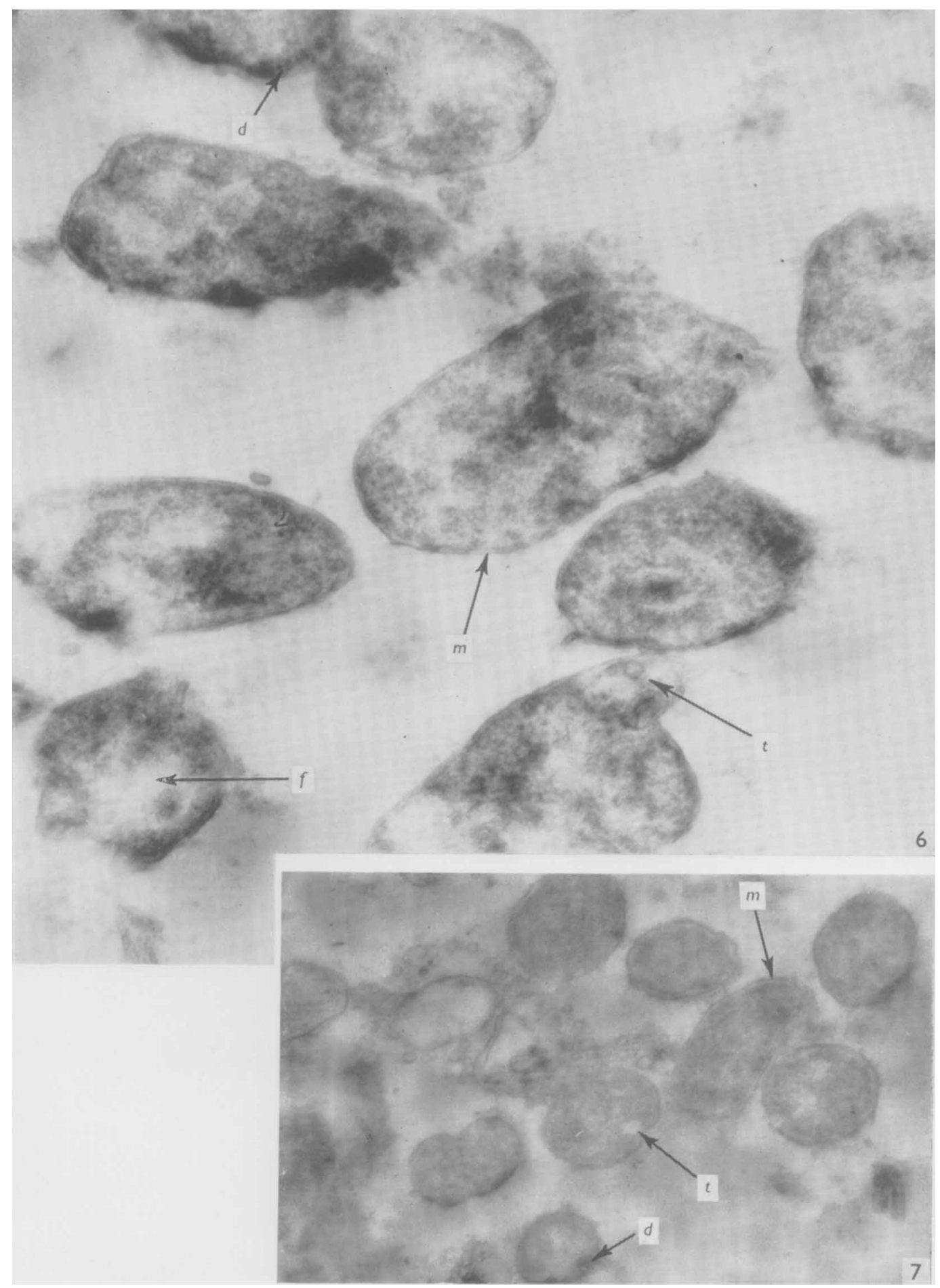

D. TAYLOR-ROBINSON AND OTHERS 